\title{
Anorectal motility in patients with achalasia of the esophagus: recognition of an esophago-rectal syndrome
} Ahmed Shafik*

\author{
Address: Department of Surgery and Experimental Research, Faculty of Medicine, Cairo University, Cairo, Egypt \\ Email: Ahmed Shafik* - shafik@ahmed-shafik.org \\ * Corresponding author
}

Published: 17 October 2003

BMC Gastroenterology 2003, 3:28
Received: 12 February 2003

Accepted: 17 October 2003

This article is available from: http://www.biomedcentral.com/l47/-230X/3/28

(C) 2003 Shafik; licensee BioMed Central Ltd. This is an Open Access article: verbatim copying and redistribution of this article are permitted in all media for any purpose, provided this notice is preserved along with the article's original URL.

\begin{abstract}
Background: During my study of constipation, I encountered patients who had achalasia of the esophagus (AE) as well. The possibility of an existing relationship between the 2 conditions was studied.

Method: Investigations to study the anorectal motility in $9 \mathrm{AE}$ patients included: the intestinal transit time, anorectal manometry, rectoanal inhibitory reflex, defecography and electromyography (EMG) of external anal sphincter and levator ani muscle. Anorectal biopsy was done. The study comprised 8 healthy volunteers as controls.
\end{abstract}

Results: 6/9 AE patients had constipation presenting as strainodynia (excessive prolonged straining at stool). Rectocele was present in 4 of them. The 6 constipated patients showed significantly high rectal neck pressure $(p<0.05)$, absent rectoanal inhibitory reflex and aganglionosis in the anorectal biopsy. The EMG revealed diminished activity in 4 of the 6 constipated patients. The remaining 3 patients with $\mathrm{AE}$ had normal anorectal function. Heller's myotomy with Nissen's fundoplication improved the dysphagia, but not the constipation which was, however, relieved after performance of anorectal myectomy.

Conclusion: The high incidence of constipation with $\mathrm{AE}$ postulates a relationship between the 2 conditions. Both have the same pathologic lesion which is aganglionosis. This study is preliminary and requires further studies on a larger number of patients.

\section{Background}

Achalasia of the esophagus (AE) is a motility disorder of controversial etiology [1-4]. Myenteric plexus degeneration impairing the lower esophageal sphincter innervation is put forward as a factor in achalasia genesis. Viral damage of the plexus is suggested as another factor [5].

During examination of 194 subjects with constipation, I came across three patients who had in addition achalasia of the esophagus. As the two conditions, $\mathrm{AE}$ and constipation, involve the gut, and as both are representative of impeded passage of its contents, we postulated a relationship between them. The current study aimed at exploring this hypothesis so as to add to the understanding of the etiology of both conditions and assist in the planning for a sound treatment. 
Table I: Clinical and investigative data of the 9 patients with achalasia of the esophagus.

\begin{tabular}{|c|c|c|c|c|c|}
\hline \multirow[t]{2}{*}{ Patients } & \multirow[t]{2}{*}{ Age } & \multirow[t]{2}{*}{ Sex } & \multicolumn{2}{|c|}{ Duration of symptoms (months) } & \multirow{2}{*}{$\begin{array}{c}\text { Radiologic findings } \\
\text { Rectocele }\end{array}$} \\
\hline & & & Constipation & Dysphagia & \\
\hline 1 & 34 & $\mathrm{~F}$ & 44 & 38 & - \\
\hline 2 & 36 & $\mathrm{~F}$ & - & 40 & - \\
\hline 3 & 41 & $\mathrm{~F}$ & 66 & 55 & + \\
\hline 4 & 40 & $\mathrm{~F}$ & 40 & 36 & - \\
\hline 5 & 35 & $\mathrm{~F}$ & 52 & 46 & + \\
\hline 6 & 38 & $\mathrm{~F}$ & 60 & 45 & + \\
\hline 7 & 36 & $\mathrm{~F}$ & - & 52 & - \\
\hline 8 & 42 & $\mathrm{~F}$ & 54 & 44 & + \\
\hline 9 & 42 & $M$ & - & 38 & - \\
\hline
\end{tabular}

Table 2: Clinical data and pressure measurements of lower esophagus, rectum and rectal neck as well as rectoanal inhibitory reflex of the 8 control healthy volunteers.

\begin{tabular}{|c|c|c|c|c|c|c|c|}
\hline \multirow[t]{2}{*}{ Patients } & \multirow[t]{2}{*}{ Age } & \multirow[t]{2}{*}{ Sex } & \multirow{2}{*}{$\begin{array}{l}\text { Stool frequency } \\
\text { (per week) }\end{array}$} & \multicolumn{3}{|c|}{ Pressure $\left(\mathrm{cm} \mathrm{H}_{2} \mathrm{O}\right)$ LES Rectal neck } & \multirow{2}{*}{$\begin{array}{c}\text { Rectoanal } \\
\text { inhibitory reflex }\end{array}$} \\
\hline & & & & LES & Rectal neck & Rectal & \\
\hline I & 32 & $\mathrm{~F}$ & 8 & 22 & 5 & 73 & + \\
\hline 2 & 38 & $\mathrm{~F}$ & 9 & 20 & 7 & 72 & + \\
\hline 3 & 37 & $\mathrm{~F}$ & 10 & 20 & 6 & 67 & + \\
\hline 4 & 44 & $\mathrm{~F}$ & 11 & 26 & 6 & 66 & + \\
\hline 5 & 40 & $\mathrm{~F}$ & 10 & 24 & 8 & 76 & + \\
\hline 6 & 35 & $\mathrm{~F}$ & 8 & 28 & 9 & 70 & + \\
\hline 7 & 42 & $\mathrm{~F}$ & 12 & 27 & 7 & 68 & + \\
\hline 8 & 39 & $M$ & 7 & 26 & 6 & 72 & + \\
\hline
\end{tabular}

\section{Methods}

The study comprised 9 patients ( 8 women, 1 man) with achalasia of the esophagus. Their clinical and investigative data are shown in table 1 . The patients gave an informed consent prior to the tests.

Barium swallow studies had provided the radiographic evidence of AE which included absent primary peristalsis, dilated body of the esophagus and a conically narrow cardioesophageal junction. Manometric studies [6] showed high pressure within, and lack of relaxation of, the lower esophageal sphincter. Esophagoscopic biopsy revealed the absence or disintegration of the ganglion cells of the Auerbach's plexus.

The anorectal motility was evaluated by means of the standardized questionnaire for anorectal symptoms, anorectal examination, intestinal transit time [7], anorectal manometry [8] rectoanal inhibitory reflex [9], defecography [10] and EMG activity of the external anal sphincter and levator ani muscle [11]. Suction rectal biopsies (Model SBT-100, Medical Measurements, Inc., Hacken- sack, NJ) were examined for the presence of ganglia in the myenteric plexus of nerves. The biopsies were stained with hematoxylin and eosin, and with silver impregnation.

Eight healthy volunteers from our laboratory, matching the test subjects in gender and age, were included in the study as controls after having given an informed consent. They had had no swallowing or anorectal complaints in the past or at the time of presentation. The clinical and investigative data are shown in table 2.

The results were analyzed statistically using the Student's t test. Differences assumed significance at $\mathrm{p}<0.05$ and values were given as mean \pm standard deviation. The study complies with the Helsinki Declaration and was approved by our Faculty Review Board and Ethics Committee.

\section{Results}

No complications were encountered during or after the performance of the tests and all of the 9 patients were evaluated. 
Six of the 9 patients with AE complained of constipation necessitating excessive straining over a long period to evacuate the bowel. Yet, the stools were soft and had a mean frequency of $8.7 \pm 1.8$ per week (range $7-12$ ), which did not differ significantly from the frequency in the control subjects ( $\mathrm{p}>0.05$; table 2 ). The remaining 3 patients defecated normally and had a mean stool frequency of 9.2 week (range 8-13). Digital rectal examination (DRE) and anoscopy were negative in the 9 patients; no hemorrhoids, fissures or fistulas were detected. In 4 of the 6 constipated patients DRE and defecography revealed a rectocele which differed in size from one patient to the other. The intestinal transit test showed accumulation of the pellets at the anorectal junction.
Manometric measurements showed a significantly high pressure in the lower esophageal sphincter of the $9 \mathrm{AE}$ patients compared to the normal controls $(\mathrm{p}<0.05$ : tables 2,3 ). The mean rectal neck pressure in the 6 constipated patients was significantly higher than in the control subjects $(\mathrm{p}<0.05$, tables 2,3$)$, whereas the rectal pressure showed no significant difference ( $p>0.05)$. The rectal and rectal neck pressures in the remaining 3 patients were normal ( $p>0.05)$. The rectoanal inhibitory reflex was absent in the 6 constipated patients whose anorectal biopsy examination showed aganglionosis (fig. 1).

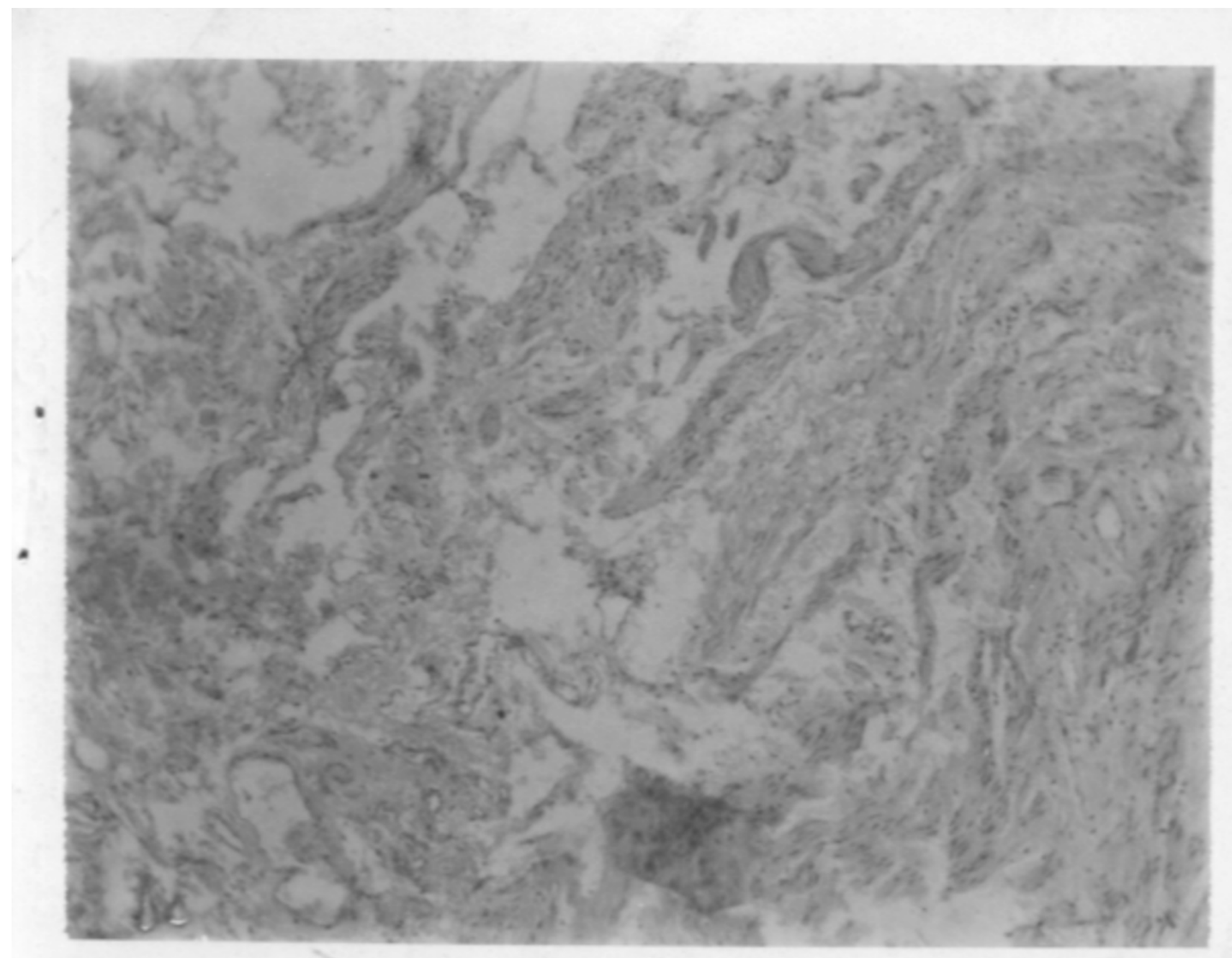

Figure I

Microphotograph showing aganglionosis of an anorectal biopsy from a patient with achalasia of the esophagus. Silver stain $\times$ 200. Arrows point to the muscle fibers; no ganglia. 
Table 3: Lower esophageal, rectal and rectal neck pressures as well as rectoanal inhibitory reflex of the 9 patients with achalasia of the esophagus+.

\begin{tabular}{ccccc}
\hline Patients & Pes & $\begin{array}{c}\text { Pressure }\left(\mathrm{cm} \mathrm{H}_{2} \mathrm{O}\right) \\
\text { Rectal }\end{array}$ & Rectal neck & Rectoanal inhibitory reflex \\
\hline 1 & 48 & 6 & 126 & - \\
2 & 62 & 7 & 52 & - \\
3 & 58 & 712 & 98 & - \\
4 & 46 & 8 & 115 & - \\
5 & 50 & 9 & 108 & - \\
6 & 63 & 7 & 68 & - \\
7 & 45 & 6 & 102 & + \\
9 & 53 & 6 & 70 & + \\
\hline
\end{tabular}

+ The numerical arrangement of the patients is the same as in table $\mathrm{I}$.

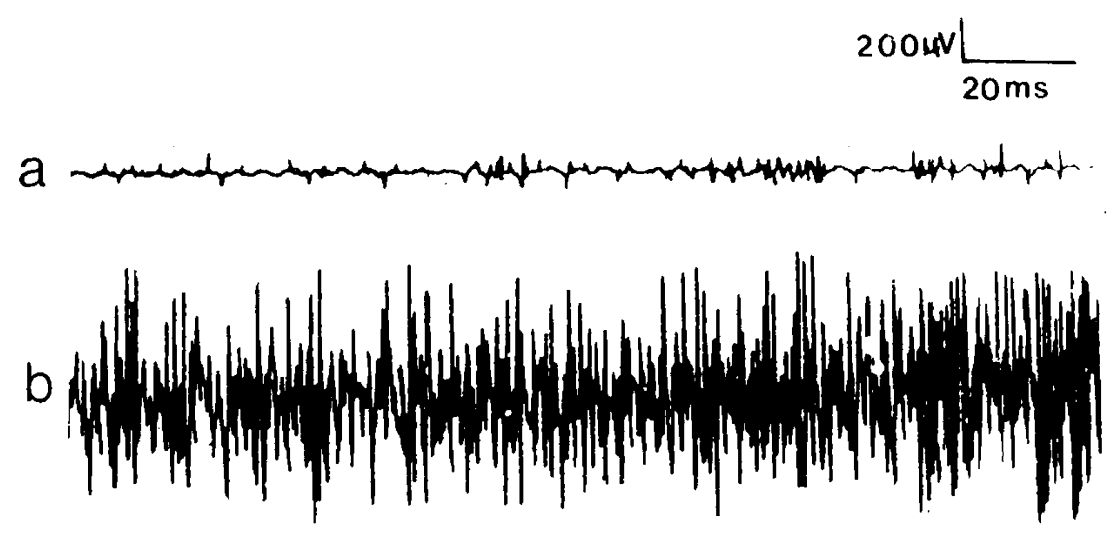

Figure 2

EMG of the external anal sphincter showing normal activity a- at rest. b- upon contraction.

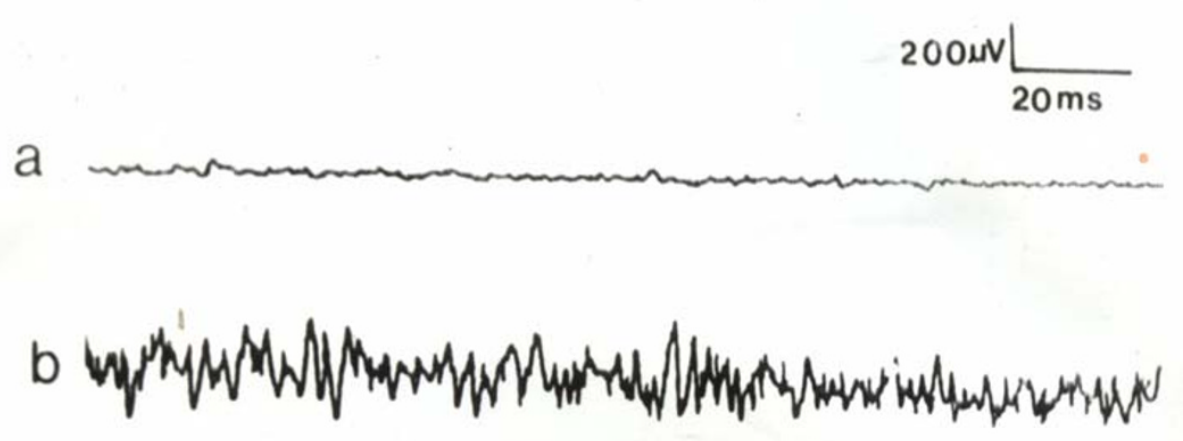

Figure 3

EMG of the levator ani muscle showing diminished activity. a- at rest. b- upon contraction. 
The EMG of the external anal sphincter was normal in all the 9 patients (fig. 2) while the levator ani showed diminished activity in 4 of the 6 constipated patients (fig. 3).

\section{Treatment}

Heller's myotomy [12] with Nissen's fundoplication were performed for the 9 patients with AE. The dysphagia improved in all the subjects. However, the constipation in the 6 patients persisted after the operation.

Considering the absence of the rectoanal inhibitory reflex and the presence of aganglionosis and high rectal neck pressure, we decided to perform anorectal myectomy for the 6 constipated patients, who gave an informed consent. Anorectal myectomy like the one done for the short segment Hirschsprung's disease [13] was carried out. The excised muscle strip showed aganglionosis. Excessive straining at stool disappeared. The rectal neck pressure decreased to a mean of $74.6 \pm 7.3 \mathrm{~cm} \mathrm{H}_{2} \mathrm{O}$ (range 66-86) which matched with the normal pressures in our laboratory.

\section{Discussion}

Of the 9 patients with $\mathrm{AE}, 6$ had constipation (66.6\%). This high incidence of constipation in AE patients postulates a relationship between the 2 conditions. Both $\mathrm{AE}$ and constipation had started later in life but constipation preceded dysphagia by a few months. This seems to rule out the assumption that constipation could result from dysphagia and diminished food intake which occur in AE.

We suggest that constipation in these patients is the result of anorectal aganglionosis. This is evidenced by the absent ganglia in both the anorectal biopsy and the strip excised at myectomy operation. Furthermore, absent rectoanal inhibitory reflex and high rectal neck pressure are encountered in anorectal aganglionosis [14]. Also, the improvement achieved by myectomy is an evidence that the constipation might be due to the anorectal aganglionosis. The normality of the EMG activity of the external anal sphincter excludes the possibility of anismus as a cause of the constipation. The accumulation of the pellets at the anorectal junction negates that the rest of the gut could be the cause. The diminished EMG activity of the levator ani muscle seems to be the result of excessive straining at stool and not a primary cause of constipation.

Operative correction of AE did not improve the anorectal manifestations. This might be viewed as indicating that there is no direct relation between the esophagus and the anorectal lesions. However, the presence of aganglionosis in both $\mathrm{AE}$ and constipated patients warrants consideration.
Although the high incidence of constipation in $\mathrm{AE}$ as well as the presence of aganglionosis in both conditions suggest a relationship between the esophageal and anorectal lesions, the current study could not elucidate its nature. The questions requiring an answer include: 1 . Why does aganglionosis occur in the two opposite and outermost segments of the gut? 2. Why did aganglionic manifestations develop later in life, thereby negating a possible congenital origin as occurs in Hirschsprung's disease? However, an acquired aganglionosis caused by cytomegalovirus or ischemia may be considered. 3. Does aganglionosis involve other parts of the gut although the intestinal transit time was normal in the rest of the gut?

It is known that the myenteric plexus of nerves extends along the whole gut [15]. Impulses can extend along this plexus from one segment of the gut to the other. Furthermore, it was found that distension of the lower esophageal sphincter induces rectal contractions mediated through an esophago-rectal reflex [16]; it was put forward that impulses extend from the esophagus to the rectum along the myenteric nerve plexus.

In conclusion, the high incidence of constipation in $\mathrm{AE}$ in the current study would draw the attention to the possible existence of a relationship between the 2 conditions which we call "esophago-rectal syndrome". This relationship needs further investigations to answer the above mentioned questions. We suggest that achalasia patients be asked about the history of constipation and vice versa constipated patients for disorders in swallowing. In the meantime, the findings of the current study warrant publication although the number of cases is small.

\section{List of abbreviations}

achalasia of the esophagus (AE)

electromyogram (EMG)

Digital rectal examination (DRE)

\section{Competing interests}

None declared.

\section{Acknowledgment}

- Professor Abdulla Khalil, Professor of Pathology at the Faculty of Medicine, Cairo University, examined the esophageal and anorectal biopsies.

- Margot Yehia and Waltraut Reichelt assisted in preparing the manuscript.

\section{References}

I. Guelrud M, Rossiter A, Souney PI, Rossiter G, Fanikes I and Mujica V: The effect of vasoactive intestinal polypeptide in the lower esophageal sphincter in achalasia. Gastroenterology 1992, 103:377-382

2. Aggestrup $S$, Uddman $R$ and Sundler $F$ et al: Lack of vasoactive intestinal peptide nerves in esophageal achalasia. Gastroenterology 1983, 84:924-927. 
3. Tottrup A, Knudsen $M$ and Gregersen $H$ : The role of the Larginine-nitric oxide pathway for lower esophageal sphincter relaxation. Br J Pharmacol I991, 104:113-116.

4. Guelrud M, Rossiter A, Souney PI and Sulbaran M: Transcutaneous electrical nerve stimulation decreases lower esophageal sphincter pressure in achalasia. Dig Dis Sci 1991, 31:1029-1033.

5. Robertson $C S$, Martin $A B$ and Atkinson : Varicella-zoster virus DNA in the esophageal myenteric plexus in achalasia. Gut 1993, 34:299-302

6. Shafik A: Electroesophagogram in achalasia of the esophagus. Dis Esoph 1996, 9:210-214.

7. Hinton JM, Lennard-Jones JE and Young AC: A new method for studying gut transit times using radio-opaque markers. Gut 1969, 10:842-847.

8. Shafik A and Moneim KA: Dynamic study of the rectal detrusor activity at defecation. Digestion I991, 49:167-174.

9. Denny-Brown $D$ and Robertson EG: An investigation of the nervous control of defecation. Brain 1935, 58:256-310.

10. Mahieu P, Pringot J and Bodart P: Defecography: II Contribution to the diagnosis of defecation disorders. Gastrointest Radiol 1984 , 9:253-261.

II. Shafik A: Ano-urethral reflex. The description of a reflex and its clinical significance. Preliminary study. Paraplegia 1992, 30:210-213

12. Ellis FH Jr: Esophagomyotomy for esophageal achalasia. S Clin North America 1973, 53:319-325.

13. Shermeta DW and Nilprabhassorn P: Posterior myectomy for primary and secondary short segment aganglionosis. $\mathrm{Am} \mathrm{J}$ Surg 1977, 133:39-42.

14. Shafik A: Electrorectogram in Hirschsprung's disease. Ped Surg Int 1995, 10:478-480.

15. Junqueira LC, Carneiro J and Long JA: Digestive tract. In: Basic Histology 5th edition. Edited by: Junqueira LC, Carneiro J, Long JA. Los Altos: Lange Medical Publications; 1986:326-353.

16. Shafik A: Esophago-rectal reflex. Description and clinical significance. Int Surg 1993, 78:83-85.

\section{Pre-publication history}

The pre-publication history for this paper can be accessed here:

http://www.biomedcentral.com/1471-230X/3/28/pre

pub
Publish with Bio Med Central and every scientist can read your work free of charge

"BioMed Central will be the most significant development for disseminating the results of biomedical research in our lifetime. "

Sir Paul Nurse, Cancer Research UK

Your research papers will be:

- available free of charge to the entire biomedical community

- peer reviewed and published immediately upon acceptance

- cited in PubMed and archived on PubMed Central

- yours - you keep the copyright
BioMedcentral 